This article was downloaded by: [Hanley, Terry][The University of Manchester]

On: 14 February 2011

Access details: Access Details: [subscription number 932319494]

Publisher Routledge

Informa Ltd Registered in England and Wales Registered Number: 1072954 Registered office: Mortimer House, 3741 Mortimer Street, London W1T 3JH, UK

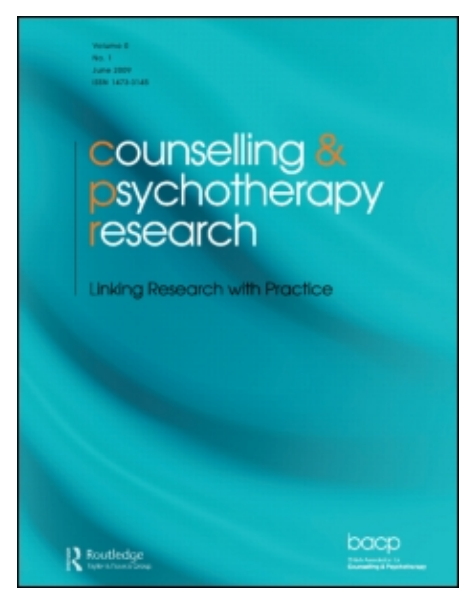

\title{
Counselling and Psychotherapy Research
}

Publication details, including instructions for authors and subscription information:

http://www.informaworld.com/smpp/title content=t713734893

\section{Practice-based evidence in school-based counselling}

Terry Hanley ${ }^{\text {a }}$, Aaron Sefi ${ }^{\text {; }}$ Clare Lennie ${ }^{\mathrm{a}}$

a University of Manchester, UK

First published on: 12 February 2011

To cite this Article Hanley, Terry, Sefi, Aaron and Lennie, Clare(2011) 'Practice-based evidence in school-based counselling', Counselling and Psychotherapy Research,, First published on: 12 February 2011 (iFirst)

To link to this Article: DOI: $10.1080 / 14733145.2010 .533778$

URL: http://dx.doi.org/10.1080/14733145.2010.533778

\section{PLEASE SCROLL DOWN FOR ARTICLE}

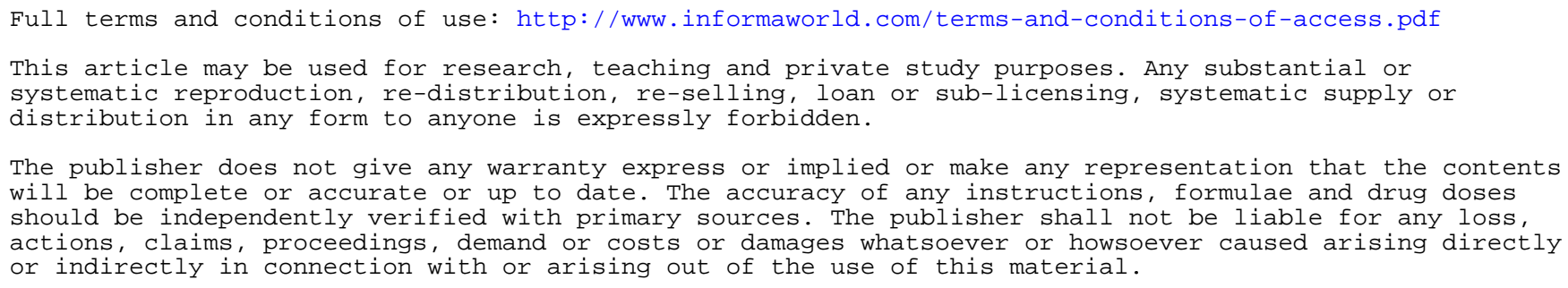




\title{
Practice-based evidence in school-based counselling
}

\author{
TERRY HANLEY^, AARON SEFI, \& CLARE LENNIE \\ University of Manchester, UK
}

\begin{abstract}
Aims: Counsellors are becoming commonplace within the support structures of secondary schools. To date, research findings from practice-based outcome studies suggest this is a positive move. There are, however, numerous limitations to this work, and this project aims to develop this existing body of literature. Method: Nine 13-15 year olds attending counselling in six school-based services participated in the project - one individual withdrew. A standardised self-report questionnaire (YP-CORE) was collected at four intervals: (1) the point of referral; (2) the onset of counselling; (3) the completion of counselling; and, (4) a two-month follow-up. The change indicated in each of these phases is examined and reported here. Additionally, YP-CORE was completed during each session. Findings: The YP-CORE indicates an improvement in the well-being of this small sample, while waiting for and attending therapy. Further examination of sessionby-session data also highlights how pre- and post-outcome data should not necessarily be viewed as linear in nature. Discussion: This is a small-scale investigation and further work is needed in this area. It does, however, raise a number of issues regarding the complexity inherent in conducting outcome research that warrant further investigation.
\end{abstract}

Keywords: counselling in schools; practice-based evaluation; outcome research; YP-CORE

\section{Introduction}

The project reported here reflects on a small-scale practice-based evaluation of school-based counselling. It examines the therapeutic affect of counselling at different stages in the process, as reported using a standardised outcome measure. In doing so, the project worked alongside a national relationship counselling organisation, Relate (which is presently delivering counselling services in approximately 625 schools in the UK), and focused upon the therapeutic work offered to 13-15-year-old pupils in six secondary schools in the north of England.

\section{Literature review}

The mental well-being of young people in the UK has received a great deal of attention in recent years. The Mental Health Foundation (MHF) claims that up to one in five children and young people experience some form of psychological problem (MHF, 1999). Furthermore, one in 10 individuals are thought to have at least one 'problem' that could be classified as a DSM-IV disorder involving a level of distress or social impairment likely to warrant treatment (Ford, Goodman, \& Meltzer, 2003; also see Green, McGinnity, Meltzer, Ford, \& Goodman, 2005).

The heightened awareness to the difficulties that adolescents face when growing up in the UK has led high-profile politicians (e.g. the first Minister for Children, Margaret Hodge, [2004]) 'think-tanks' (Sodha \& Margo, 2008), and national children's charities (e.g. National Society for the Prevention of Cruelty to Children [NSPCC], 2004) to call for all young people to have access to professional counselling. Such voices have led to the development of therapeutic services for young people outside of traditional clinical settings. Developments in community settings (e.g. Hanley \& Morrison, 2003), on the internet (e.g. Hanley, 2004) and in secondary schools (e.g. Bor, Ebner-Landy et al., 2002), have therefore emerged. Regarding the latter, the acknowledgement of the need to cater for young peoples' emotional well-being has moved up the agenda in recent years.

In England, recent government projects to improve the social, emotional and behavioural skills of

^Corresponding author: Email: terry.hanley@manchester.ac.uk

ISSN 1473-3145 print/1746-1405 online (C) 2011 British Association for Counselling and Psychotherapy DOI: $10.1080 / 14733145.2010 .533778$ 
young people within schools have begun to be rolled out across the country (see the Social and Emotional Aspects of Learning [SEAL] whole-school approach to supporting young people [Department for Education and Skills, 2005] and the Targeted Mental Health in Schools [TaMHS] initiative [Department for Children, Schools and Families, 2008] for overviews of these projects). More specifically related to counselling provision, approximately $75 \%$ of schools now report having a counsellor available for students to access (Jenkins \& Polat, 2005). Outside of England, it is also noteworthy that counsellors are being introduced in all secondary schools in Wales (Welsh Assembly Government, 2008), and postprimary schools in Northern Ireland (Northern Ireland Office, 2006), and there is a policy target for providing counselling in Scottish schools and communities by 2015 (Public Health Institute of Scotland, 2003).

The qualitative research exploring young clients' experiences of school-based counselling is presently limited. A number of projects have looked at individuals' perceptions or experiences of counselling (e.g. Chan \& Quinn, 2009; Cooper, 2006b; Pattison, Rowland et al., 2007; Quinn \& Chan, 2009). However, these have predominantly focused upon input variables (e.g. the sex of the counsellor), rather than the inner workings of the counselling relationship and outcomes. In synthesising the research in this latter area, Cooper (2009) outlines that school-based counselling is often perceived to be helpful, and that there is a general feeling of satisfaction from stakeholder groups (e.g. young people and teachers).

Despite the growing number of schools that provide access to counselling, and the reported satisfaction levels, little research has been conducted into the effectiveness of such work. Within a comprehensive review by Cooper (2009), the findings from 30 audit and evaluation studies conducted in the UK have been summarised. This reflects upon the experiences of approximately 10,830 clients with counsellors reporting to work from person-centred or integrative therapeutic approaches. At the point of writing, this paper provides the most significant review of its kind and begins to indicate that such services are beneficial to young people.

Although the findings noted look relatively positive for school-based counselling, there is a downside. Cooper (2009) highlights numerous weaknesses in the quality of the data. Most notably, none of the studies included a comparison group to reflect upon how individuals may have coped without an intervention. Such an omission raises major questions about what can be inferred from the data. For instance, although an impressive change is reported from the beginning to end of counselling by a large number of young people, numerous questions can be asked of the data. These include: (1) How do we know that improvement is due to the therapeutic intervention? (2) How many people did not complete the questionnaires? (3) How do we know that the change sustained will last beyond the final session?, and (4) How do we know that the findings are not a reflection of the questionnaires being used?

In response to the limited quality of data in existing studies, a feasibility study into conducting a randomised controlled trial (RCT) examining school-based counselling services has been undertaken (Cooper, Rowland, McArthur, Cromarty, Pattison, \& Richards, 2010). This study displayed the potential for using such a research method within the 'messy' school environment. More worryingly for such services, it indicated that the counselling intervention appeared to be no more useful than a period waiting for counselling in this instance. There were limitations to the study that are highlighted by the authors, however, without a doubt such a conclusion raises some important questions for the future of school-based counselling services.

\section{Practice-based evidence}

In recent years the philosophy of practice-based evidence has raised questions about traditional hierarchies of evidence that place in high regard the RCT (e.g. Barkham et al., 2010). Such strategies have produced findings utilising data from large numbers of adult clients (e.g. Stiles et al., 2006, 2008). However, as identified by Cooper (2009), they are easily criticised for the omission of a comparison group (e.g. Clark, Fairburn, \& Wessely, 2008). One study which focuses upon personcentred counselling in primary care and utilised the adult CORE-OM questionnaire (Barkham et al., 2006) as a real world research tool is that of Gibbard and Hanley (2008). This introduced a comparison element to the study by reflecting upon the change indicated during a period of waiting for therapy. This multiple baseline approach meant that a comparison between change indicated while waiting for therapy could be compared to change indicated whilst within therapy. Such data create a compelling argument for 
the use of such interventions within primary care settings.

\section{Research questions}

This project considered two major research questions:

- Question 1. Will pupil self-report outcome measures indicate reductions in psychological distress following a period of counselling? Embedded in this question are the following sub questions: How does any change reported compare to (a) the findings of other studies? and, (b) the change indicated during the time from teacher referral to the onset of counselling?

- Question 2. How do session-by-session outcome measure scores indicate change occurs?'

\section{Methodology}

This study utilised a quantitative measure to explore the potential affect of therapy upon the well-being of a small sample of young people. This paper presents an initial layer of a larger project in which an additional outcome measure has been used and qualitative interviews have been conducted.

\section{Participants: Schools, counsellors and adolescents}

This study was conducted in partnership with Relate. In total, six secondary schools in the north west of England that had a Relate service took part. Each of these schools was informed about the project and supported the project aims. The teaching staff in these schools acted as the point of referral into the work.

Four Relate counsellors, who offered the counselling services in the six secondary schools, took part. Each counsellor was trained to a minimum of a UK Diploma level and all described their practice as integrative in orientation (i.e. valuing the relationship but also utilising more technical interventions where appropriate). Additionally, they had all completed Relate's training to work with young people and attended a half-day training course focusing upon the purpose of the project. The contracted length of therapy differed dependent upon the specific needs of the client referred.

All young people within years nine and 10 (ages 13-15) referred to the counselling services over a five-month period in 2009-2010 were invited to participate in the research project. Recruitment was purposefully limited so that only young people assessed as competent to give informed consent took part in the study. This was felt particularly important, as all clients would have to complete numerous questionnaires during their contact with the service; this totalled nine young people. One young person decided to withdraw during the study and did not wish the questionnaires they had completed to be used. This study therefore reflects work with eight clients between the ages of 13 and 15. Seven of these were female and one was male. It is noteworthy that although this is a small sample, its near completeness $(89 \%$ of the overall possible population taking part) indicates a strength of the project.

\section{Data collection: YP-CORE}

The YP-CORE Outcome Measure (Young Person's Clinical Outcomes in Routine Evaluation: Twigg, Barkham, Bewick, Mulhern, \& Cooper, 2009) was used to monitor therapeutic change during counselling. This is a questionnaire designed for routine administration with young people. Particular strengths for use with this client group include its brevity, consisting of only 10 questions, and that it has been utilised successfully to assess youth counselling in the past (e.g. Cooper, 2006b, 2007).

\section{Procedure}

There were five key data collection points:

- Referral from teacher - the young person completed CORE-YP (facilitated by the referring teacher).

- Onset of counselling - the young person completed CORE-YP (facilitated by the counsellor).

- At the beginning of every counselling session - the young person completed CORE-YP (facilitated by the counsellor).

- The final counselling session - the young person completed CORE-YP (facilitated by the counsellor).

- Two months after the final counselling session - the young person completed CORE-YP and SDQ (facilitated by the counsellor).

Box 1 summarises the timescales of the periods of waiting, counselling and the period until follow up. 
Box 1. The timescales of the periods of waiting, counselling and the period until follow up.

The average period waiting for counselling was: mean $=17.4$ days, mode $=7$ days

The average intervention for completed work $(n=6)$ was: mean $=5.3$ sessions, mode $=4$

The mean period to follow up $(n=5)$ was: 8.4 weeks (longest 11 weeks, shortest 5 weeks).

Along with these data, both the student and teacher completed the Strengths and Difficulties Questionnaire (SDQ: Goodman, 1998) at data collection points $1,2,4$ and 5 , and individuals were invited to take part in qualitative interviews at the end of counselling. Due to limits of space and the limited number of interviews conducted $(n=2)$ these data are not discussed in this paper.

\section{Data analysis}

Initially the YP-CORE data were summarised in relation to the key data collection points. Descriptive statistics were calculated, including the Mean and Standard Deviation for the results. The following comparisons were then made:

(1) The pre- and post-counselling data were considered in relation to benchmarks for the YP-CORE (see Twigg et al., 2009);

(2) The difference between scores at the point of referral and the onset of counselling was compared to difference in scores between the onset of counselling and the end of counselling.

Table I summarises the different assessment points when interpreting the CORE-YP as indicated alongside the YP-CORE form (CORE, 2009).

The second analysis reflects on the session-bysession YP-CORE data.

Table I. Interpreting the YP-CORE.

\begin{tabular}{lc}
\hline Level of distress & Score \\
\hline Severe & $26-40$ \\
Moderate Severe & $21-25$ \\
Moderate & $16-20$ \\
Mild & $11-15$ \\
Low Level & 10 and below (Clinical Cut Off)
\end{tabular}

\section{Ethical considerations}

As this project worked directly with potentially vulnerable young people, care was taken to ensure the well-being of those involved. The work adhered to the Health Professions Council's (HPC) standards of conduct, performance and ethics (HPC, 2009), and the British Psychological Society's (BPS) code of ethics (BPS, 2006; also see the BPS's statement regarding conducting research with human participants [BPS, 2004]). Additionally the work was granted ethical approval by the University Research Ethics Committee.

\section{Findings}

\section{Overall scores}

In reflecting on the data set as a whole, Table II summarises the data at the key intervals. This provides a summary of the number of people who took part in this particular element of the study, the minimum and maximum YP-CORE score, the mean score and the standard deviation.

From the data presented here it is notable that there is a steady decrease in the mean YP-CORE scores (thus indicating an increase in well-being) during both the period waiting for counselling (from 23 to 17) and the period in counselling (from 17 to 11 ).

Table III outlines the self-reported YP-CORE scores for each of the eight clients who agreed for their information to be used. These data are also summarised graphically in Figure 1. Note that, unlike many reports of outcomes, line graphs were not utilised to present these data. This decision was

Table II. Table outlining the mean values and standard deviations for the YP-CORE data.

\begin{tabular}{lccccr}
\hline & $n$ & Minimum & Maximum & $M$ & $S D$ \\
\hline Referral & 8 & 12 & 40 & 23.13 & 10.18 \\
Onset & 8 & 8 & 37 & 17.38 & 10.16 \\
End & 6 & 6 & 22 & 10.83 & 5.88 \\
Follow Up & 5 & 7 & 21 & 12.40 & 6.58 \\
\hline
\end{tabular}

Table III. Summary of the YP-CORE scores at key data collection points ( $\mathrm{w}=$ ongoing).

\begin{tabular}{lrrrrrrrr}
\hline Client & 1 & 2 & 3 & 4 & 5 & 6 & 7 & 8 \\
\hline Referral & 14 & 21 & 29 & 20 & 34 & 40 & 12 & 15 \\
Onset & 8 & 10 & 29 & 15 & 13 & 37 & 15 & 12 \\
End & 7 & 10 & 8 & 12 & w & 22 & w & 6 \\
Follow Up & 7 & 18 & 8 & 8 & w & w & w & 21 \\
\hline
\end{tabular}






Figure 1. The self-reported YP-CORE scores for each of the eight clients.

made so as not to suggest a linear process between the key data collection points. In Figure 1 each client's YP-CORE scores at key intervals are summarised in turn.

In considering the impact of the intervention period, the 'distance travelled' (i.e. difference between YP-CORE collected at key intervals scores) is possible to calculate. These are presented in Table IV, and indicate that positive change occurred while waiting for counselling (six out of eight individuals showing some improvement), and while in counselling (five out of six individuals showing some improvement). Only five individuals from the initial sample completed follow up questionnaires. These indicated that two clients showed no change in YPCORE scores following counselling, one decreased slightly and two increased.

\section{Session-by-session data}

During therapy it is possible to examine the trajectory of therapeutic affect by plotting the YPCORE scores. Figures 2-9 plot the session-bysession YP-CORE scores as indicated by each individual client. As is evident in the scores, the progress through counselling has varied greatly for these clients.

\section{Discussion}

The findings of this small-scale study provide an insight into the lifespan of the therapeutic relationship as reported using outcome measures. They indicate that the clients involved in this project showed improvements in their well-being, both during the period waiting for therapy and the period in therapy. Furthermore, they go some way to highlighting the complexity inherent in conducting quantitative outcome studies.

A major area of interest is the idea of waitlist improvement. Six out of eight young people involved showed some signs of improvement during this period. Where comparisons to a period in counselling can be made ( $n=6$ - two clients were still attending counselling when data collection for this project ended), this change proved larger than the distance travelled whilst in therapy for three young people. Thus, more positive change was reported on the waiting list than whilst in counselling. Additionally, this waiting period often proved shorter than the period in counselling itself. Such a finding might raise questions in line with those outlined by Eysenck (1952) during the middle of the last century - notably, 'Does counselling show itself to be more effective than a period of non-intervention?'

Table IV. The distance travelled during a period of waiting, counselling and follow up.

\begin{tabular}{|c|c|c|c|c|c|c|c|c|}
\hline Client & 1 & 2 & 3 & 4 & 5 & 6 & 7 & 8 \\
\hline ref-onset & -6 & -11 & 0 & -5 & -21 & -3 & 3 & -3 \\
\hline onset-end & -1 & 0 & -21 & -3 & $\mathrm{w}$ & -15 & $\mathrm{w}$ & -6 \\
\hline end-follow up & 0 & 8 & 0 & -4 & $\mathrm{w}$ & $\mathrm{w}$ & $\mathrm{w}$ & 15 \\
\hline
\end{tabular}


6 T. Hanley et al.


Figures 2-9. The session-by-session YP-CORE scores as indicated by each individual client.

${ }^{\star}$ Please note clients 5 and 7 were still attending counselling at the point data collection ended. 
It also complements the findings from the recent RCT which indicated that school-based counselling fared no better than a period of waiting for counselling (Cooper et al., 2010). However, as indicated within the literature, there is further complexity requiring consideration.

Cooper's (2009) review highlighted a positive movement using outcome measures for many young people. Although we cannot say accurately how these findings may have compared to a non-intervention period (such as that utilised by Cooper et al., 2010), and how many individuals did not complete the questionnaires, it is noteworthy that the qualitative narratives from young people who attended counselling also explicitly reported the value for such services. Within this study, two qualitative interviews were conducted with the young people who had completed a period of counselling (Clients 6 and 8). Interestingly, given the varied session-by-session YP-CORE scores, both their views were highly supportive of the services they had attended. When asked what they thought were the weaknesses or unhelpful aspects of the services, the following responses were given:

I don't really think there were any weaknesses. (Client 6)

I don't think anything was unhelpful. I think all of it was good. I think all of it was brilliant. I don't think there was anything bad about it at all. (Client 8)

Alternative explanations may therefore be needed to explain the reduction of distress while on the waiting list. For instance, an individual's life circumstances may fluctuate quickly, the questionnaires used may not have captured appropriate information, the offer of counselling may prove therapeutic in itself, or in reaching out for support the client may have already initiated an important step towards positive change. Additionally, further understanding of what counselling services offer in schools may need to be considered. For instance, do counselling services contribute to the broader well-being of the school community in the way that the Social and Emotional Aspects of Learning (SEAL) initiative intends (DfES, 2005), rather than just treating psychopathological symptoms?

For five of the young people who had completed counselling, the intervention period suggested some benefits to their general well-being. The final young person's score remained the same. Such a finding resonates with the positive findings of Cooper (2009). As the size of the sample is not large enough to calculate a satisfactory effect size, the overall 'distance travelled' between key data collection point intervals has to be relied upon (see Table IV). Based on these scores, and linking these findings to the clinical cut-off threshold for the questionnaire (Twigg et al., 2009), the following can be noted about the key stages being examined:

- the reduction of distress reported by clients while on a waiting list is observable. Six out of eight clients show some reduction in distress; two individuals' scores reduce below the clinical change cut off threshold;

- the reduction of distress reported by clients whilst in therapy is observable. Five out of six clients show some reduction in distress - two individuals' score reduce below the clinical change cut off threshold; and

- the follow up data noted three out of five clients remained under the clinical cut off level (one reducing following therapy). Two individuals moved from indicating a low level of distress to a moderate/severe level following therapy.

The scores therefore indicate that during the period of being in contact with the counselling service, progress had occurred in all instances, and has been sustained for three out of the five individuals who have been followed up. In considering these findings in relation to the existing benchmarks provided, a useful rule for reliable change, similar to that noted for using the adult CORE (see Barkham et al., 2006), would be helpful.

The complexity of telling the therapeutic story through outcome measures is compounded by the session-by-session data collected. Other research illustrates outcome data as a simple two-stage process in which clients move neatly from point $A$ at the beginning of therapy, to point $B$ at the end of therapy. This is a sentiment also reflected in Table II of this paper in which mean data are summarised simply to make them easily digestible. As is evident within Figures 2-9, this does not prove to be quite so straightforward in the data collected here. While Client 3 unfolds into something akin to how data are often presented in such reports, the other seven 
figures (two of which reflect ongoing counselling) show incredibly varied pictures. Perhaps here, it is worth noting that within the five fully completed reports, the only observable pattern appears to be one of difference, in that no single report reflects another's process. Such a sentiment supports the notion that exploring clients' experiences in this way can be incredibly rich, and that the headlines created from such data need to be viewed in a way that is sympathetic to the complexity of the client's experiences.

This project attempted to generate sufficient practice-based data to examine the lifespan of counselling relationships within school-based counselling services. Although the numbers recruited into the study proved relatively small, and thus a major limitation, the data themselves prove rich and pose much food for thought. A major strength to the data collection process was that eight out of nine individuals recruited into the study agreed to participate and allowed for their data to be used. It was also thought that this small number proved ethically appropriate for an exploratory study with potentially vulnerable young people as participants.

The naturalistic school setting proved another challenge. Although both the practitioners and schools were very supportive of the work, there were many elements that could not be controlled. For instance, within earlier research utilising a waiting list comparison group with adult clients, this period proved significantly longer than the intervention period (Gibbard \& Hanley, 2008). In this instance, the waiting period generally proved considerably shorter (mode waiting period $=$ one week; mode intervention period $=$ four weeks). The 'messiness' of real world research (Robson, 2002) unfortunately makes comparing like with like very difficult. Such a challenge may also be increased when considering fluctuations in school referral systems, the presenting issues of young people and therapeutic styles of counsellors.

At the outset of the project it was feared that the intensive nature in which questionnaires were requested would prove off putting to the young clients. In contrast, within both interviews conducted, the young people expressed the process to be useful.

It's been fine. Completing the questionnaires has been quite helpful as well. 'Cos there's different questions on different things that even you forget about when you come in and it helps you get a problem from that. (Client 6 , on completing the questionnaires in the research project)

I think the questions are really useful. At least someone knows what I've been doing and stuff like that. (Client 8, when considering YP-CORE)

\section{Conclusions and future research}

This project has raised more questions than answers about the delivery of school-based counselling. Additionally, it has highlighted numerous challenges for undertaking research in this environment. In relation to whether pupil self-report outcome measures indicated reductions in psychological distress following a period of counselling (RQ1), five out of six young people who had completed counselling showed improvement during this intervention period. In this instance, this did not appear as effective as those reported by Cooper (2009), but there are numerous reasons why this may prove to be the case and further larger scale systematic research is needed in this area. In addition, the period of waiting for counselling proves an area that is little understood and one in need of more investigation.

When considering how session-by-session outcome measure scores indicate change (RQ2), it is notable that the process is far from linear in nature. Each of the eight plots of YP-CORE scores displays a unique therapeutic story with different twists and turns. Such aspects of outcome studies (controlled and naturalistic in nature) need to be considered further. This may include examining quantitative data alongside qualitative approaches to gain more detailed insights into the complexities of therapeutic encounters. Practitioners and researchers may also find the young peoples' positive experiences of involvement in this project useful when considering whether to enter into such work.

\section{Acknowledgements}

This project was funded by the School of Education Research Support fund at the University of Manchester and Relate national. Particular thanks are expressed to the young people who took part in the project, the counsellors from Relate GMS involved and the secondary schools who very kindly supported the project. 


\section{References}

Barkham, M., Mellor-Clark, J., Connell, J., \& Cahill, J. (2006). A core approach to practice-based evidence: A brief history of the origins and applications of the CORE-OM and CORE System. Counselling and Psychotherapy Research, 6 (1), 3-15.

Barkham, M., Stiles, W., Lambert, M., \& Mellor-Clark, J. (2010). Building a rigorous and relevant knowledge base for the psychological therapies. In M. Barkham, G. Hardy \& J. Mellor-Clark (Eds.), Developing and delivering practice-based evidence: $A$ guide for the psychological therapies (pp. 21-62). Chichester: Wiley-Blackwell.

Bor, R., Ebner-Landy, et al. (2002). Counselling in schools. London: Sage.

British Psychological Society (BPS). (2006). Code of ethics and conduct. Leicester: BPS.

British Psychological Society (BPS). (2004). Guidelines for minimum standards of ethical approval in psychological research. Leicester: BPS.

Chan, S., \& Quinn, P. (2009). Secondary school students' preferences for school counselors to be of the same ethnic origin as themselves. Counselling and Psychotherapy Research, 9 (3), 210-218.

Clark, D., Fairburn, C., \& Wessely, S. (2008). Psychological treatment outcomes in routine NHS services: A commentary on Stiles et al. (2007). Psychological Medicine, 38, 629-634.

Clinical Outcomes in Routine Evaluation (CORE) (2009) YPCORE. Rugby: CORE System Trust.

Cooper, M., Rowland, N., McArthur, K., Cromarty, K., Pattison, S., \& Richards, K. (2010). Randomised controlled trial of school-based humanistic counselling for emotional distress in young people: Feasibility study and preliminary indications of efficacy. Child and Adolescent Psychiarty and Mental Health, 4 (12), 1-12.

Cooper, M. (2006a). Counselling in Schools Project, Glasgow, Phase II: Evaluation report. Glasgow: University of Strathclyde.

Cooper, M. (2006b). Scottish secondary school students' preferences for location, format of counselling and sex of counsellor. School Psychology International, 27 (5), 627-638.

Cooper, M. (2007). Therapeutic counselling in schools: A review of current research. Society for Psychotherapy Research UK Chapter Conference, Ravenscar: SPR.

Cooper, M. (2009). Counselling in UK secondary schools: A comprehensive review of audit and evaluation data. Counselling and Psychotherapy Research, 9 (3), 137-150.

Department for Children, Schools and Families. (2008). Targeted Mental Health in Schools project: Using the evidence to inform your approach: A practical guide for head teachers and commissioners. London: DCSF.

Department for Education and Skills. (2005). Excellence and enjoyment: Social and emotional aspects of learning (guidance). Nottingham: DfES.

Eysenck, H. (1952). The effects of psychotherapy. In H. Eysenck (Ed.), Handbook of abnormal psychology. New York: Basic Books.

Ford, T., Goodman, R., \& Meltzer, H. (2003). The British Child and Adolescent Mental Health Survey 1999: The Prevalence of DSM-IV Disorders. Fournal of the American Academy of Child and Adolescent Psychiatry, 42 (10), 1203-1211.

Gibbard, I., \& Hanley, T. (2008). An evaluation of the effectiveness of person centred counselling in routine clinical practice in primary care. Counselling and Psychotherapy Research, 8 (4), 215-222.

Goodman, R. (1998). The Strengths and Difficulties Questionnaire: A pilot study on the validity of the self-report version. European Child and Adolescent Psychiatry, 7, 125-130.

Green, H., McGinnity, A., Meltzer, H., Ford, T., \& Goodman, R. (2005). Mental health of children and young people in Britain. London: Palgrave.

Hanley, T. (2004). E-Motion Online. Counselling and Psychotherapy fournal, 15 (1), 48-49.

Hanley, T., \& Morrison, R. (2003). Visyon. Accessible services for 11 to 25 year olds. Child and Adolescent Mental health in Primary Care, 1 (3), 89-91.

Health Professions Council (HPC). (2008). Standards of conduct, performance and ethics. London: HPC.

Hodge, M. (2004). Virtual conversations. Counselling in Education, Spring, 14-15.

Jenkins, P., \& Polat, F. (2005). The current provision of counselling services in secondary schools in England and Wales. Manchester: University of Manchester.

Mental Health Foundation (1999). Bright futures: Promoting children and young people's mental health. London: Mental Health Foundation.

Northern Ireland Office. (2006). Press release. Retrieved April 12, 2010, from http://www.nio.gov.uk/media-detail.htm?newsID $=$ 12831

National Society for the Prevention of Cruelty to Children (NSPCC). (2004). Someone to turn to. London: NSPCC.

Pattison, S., Rowland, N., Cromarty, K., Richards, K., Jenkins, P., Cooper, M., et al. (2007). Counselling in schools: A research study into services for children and young people in Wales. Lutterworth, Leicestershire: BACP.

Public Health Institute of Scotland. (2003). Needs assessment report on child and adolescent mental health. Edinburgh: Public Health Institute of Scotland.

Quinn, P., \& Chan, S. (2009). Secondary school students' preferences for location, format of counselling and gender of counsellor: A replication study based in Northern Ireland. Counselling and Psychotherapy Research, 9 (3), 204-209.

Robson, C. (2002). Real world research (2nd edn). London: John Wiley \& Sons.

Sodha, S., \& Margo, J. (2008). Thursday's child. Newcastle Upon Tyne: Institute for Public Policy Research.

Stiles, W., Barkham, M., Mellor-Clark, J., \& Connell, J. (2008). Effectiveness of cognitive-behavioural, person-centred, and psychodynamic therapies in UK primary-care routine practice: Replication in a larger sample. Psychological Medicine, 38, 677688.

Stiles, W., Barkham, M., Twigg, E., Mellor-Clark, J., \& Cooper, M. (2006). Effectiveness of cognitive-behavioural, person-centred, and psychodynamic therapies in UK National Health Service settings. Psychological Medicine, 36, 555-566.

Twigg, E., Barkham, M., Bewick, B., Mulhern, B., Connell, J., \& Cooper, M. (2009). The Young Person's CORE: Development of a brief outcome measure for young people. Counselling and Psychotherapy Research, 9 (3), 160-168.

Welsh Assembly Government. (2008). School-based counselling services in Wales: A national strategy. DELLS, Cardiff: Welsh Assembly Government. 


\section{Biographies}

Terry Hanley is joint programme director of the Doctorate in Counselling Psychology at the University of Manchester. He is also the research lead for the British Psychological Society's Division of Counselling Psychology and Editor of Counselling Psychology Review.
Aaron Sefi is an MA student at the University of Manchester and youth counsellor.

Clare Lennie is joint programme director of the Doctorate in Counselling Psychology at the University of Manchester. 